\title{
Um Pesquisador em Computação em Busca de um Modo de FazerPensar Pesquisas em Informática na Educação
}

\author{
Title: A Computer Science Researcher Looking for a Way to ThinkDo the Research on \\ Computers in Education
}

\author{
Mariano Pimentel \\ Departamento de Informática Aplicada \\ Universidade Federal do Estado do Rio de Janeiro (UNIRIO) \\ pimentel@uniriotec.br
}

\begin{abstract}
Resumo
Neste artigo, com base no método "história de vida autobiográfica", narro minha história em busca de um modo de realizar e orientar pesquisas úteis e rigorosas na área de Informática na Educação. Para me ajudar a tecer este relato, trago dados do meu histórico de publicações no SBIE (Simpósio Brasileiro de Informática na Educação), WIE (Workshop de Informática na Educação) e RBIE (Revista Brasileira de Informática na Educação). Relato como minha práxis de pesquisa científica foi se transformando nas últimas décadas até chegar na apropriação da abordagem epistemológica Design Science Research para conceber o desenvolvimento de artefatos em minhas pesquisas científicas, e na abordagem epistemológica Pesquisas com os Cotidianos Escolares como uma alternativa ao Positivismo para a realização de estudos empíricos. Com a narrativa de minhas vivências, lutas e conflitos em busca de um modo para realizar e orientar pesquisas que eu reconhecesse como científicas, objetivo apontar para a importância de discutirmos os pressupostos epistemológicos de nossas pesquisas, e com isso espero contribuir para a melhoria das produções cientificas de nossa comunidade brasileira de pesquisadores em computação atuantes em Informática na Educação.
\end{abstract}

Palavras-Chave: Informática na Educação; Pesquisa Científica; Metodologia; Epistemologia; Design Science Research; Pesquisas com Cotidianos Escolares.

\begin{abstract}
In this paper, following an autobiographical research methodology, I tell my academic history in the pursuit of conducting and guiding rigorous researches on computers in education. I illustrate my narrative by citing my publication history in the SBIE (Brazilian Symposium on Computers in Education), the WIE (Workshop on Informatics in School) and in the RBIE (Brazilian Journal of Computers in Education). I also present the reasons that led me to adopt the epistemological approach Design Science Research in the development of artefacts in scientific researches, as well as the Everyday Life's School Studies as an alternative to positivism in the conduction of empirical studies. By telling my academic history, and by showing the importance of discussing the epistemological presuppositions of our research work, I aim at contributing to an increase in the quality of the researches developed by the community of Brazilian scholars that focus on computers in education.
\end{abstract}

Keywords: Computers in Education; Scientific Research; Methodology; Epistemology; Design Science Research; Everyday Life Studies.

Cite as: Pimentel, M. (2018). A Computer Science Researcher Looking for a Way to ThinkDo the Research on Computers in Education (Um Pesquisador em Computação em Busca de um Modo de FazerPensar Pesquisas em Informática na Educação). Brazilian Journal of Computers in Education (Revista Brasileira de Informática na Educação - RBIE), 26(1), 51-69. DOI: 10.5753/RBIE.2018.26.01.51 


\section{Oue é e como se faz pesquisa em Informática na Educação?}

Todos nós, pesquisadores que publicamos nos eventos e periódico promovidos pela $\mathrm{SBC}^{1}-$ $\mathrm{SBIE}^{2}, \mathrm{WIE}^{3}$ e $\mathrm{RBIE}^{4}$-, já nos questionamos como fazer pesquisas em Informática na Educação. Tentar responder essa questão, ainda que provisoriamente, implica questionarmos as diferentes possibilidades para fazerpensar ${ }^{5}$ uma pesquisa científica, o que nos possibilita refletir sobre as pesquisas que realizamos e (re)pensar como queremos fazer pesquisas nos próximos anos.

Neste artigo, relato como minha práxis de pesquisa científica foi se transformando nas últimas décadas e discuto as abordagens epistemológicas-metodológicas que eu e o grupo de pesquisa que coordeno nos apropriamos para fazerpensar as pesquisas em Informática na Educação na atualidade. Trago alguns dados do meu histórico de publicações no SBIE, WIE e RBIE para me ajudar a tecer este relato, que está baseado no método "história de vida autobiográfica":

Escreve Becker (1986) que a autobiografia proporcionada pela técnica de história de vida se propõe a nos contar a vida de um ser engajado; há um esforço em manter uma coerência entre a história que ele narra e aquilo que uma investigação objetiva quer descobrir. (...) Reafirmando o caráter ao mesmo tempo fenomenológico e científico do recurso metodológico da história de vida, Becker (1986) observa que a biografia narrada pode ser particularmente útil para esclarecer o lado subjetivo de processos institucionais. (...) $\mathrm{Na}$ elaboração de Ferraroti (1983), se cada sujeito representa a reapropriação singular do universo social e histórico que o envolve, podemos ter a pretensão de conhecer o social a partir da especificidade de uma práxis individual. De fato, para o autor, cada sujeito totaliza a sociedade pela mediação de seu contexto social mais próximo, isto é, dos grupos específicos do qual faz parte em seu dia-a-dia. (...) Trata-se, então, de retomar a riqueza e a importância das recordações dos sujeitos humanos, devolvendo às pessoas que fizeram, e fazem, a história um lugar fundamental, mediados por suas próprias palavras. (Macedo, 2006, p.111-113)

Por meio de minha história autobiográfica, espero expor, em parte, a evolução das práticas de pesquisa da comunidade brasileira de pesquisadores em computação atuantes em Informática na Educação ao longo das últimas décadas, pois minha história foi parcialmente tecida com essa comunidade na qual me formei e ainda me formo pesquisador-orientador.

Narro minhas experiências e reflito sobre minha itinerância em busca de um modo para realizar e orientar pesquisas rigorosas em Informática na Educação. Ao narrar minhas lutas e conflitos problematizando minha identidade enquanto pesquisador-orientador nessa área, uma identidade fluida, em constante construção, busco ressaltar a importância de discutirmos os pressupostos epistemológicos de nossas pesquisas científicas, e com isso espero contribuir para a melhoria das produções científicas de nossa comunidade.

\footnotetext{
${ }^{1}$ Sociedade Brasileira de Computação - http://www.sbc.org.br

${ }^{2}$ Simpósio Brasileiro de Informática na Educação - http://www.br-ie.org/pub/index.php/sbie

${ }^{3}$ Workshop de Informática na Escola - http://www.br-ie.org/pub/index.php/wie

${ }^{4}$ Revista Brasileira de Informática na Educação - http://www.br-ie.org/pub/index.php/rbie

${ }^{5}$ Como recorrentemente praticado nas Pesquisas com os Cotidianos Escolares, esses termos foram aqui grafados juntos para indicar a não-separação entre o fazer e o pensar, uma licença ortográfica para desconstruir as dicotomias que organizaram o pensamento das ciências na Modernidade.
} 


\section{Desenvolvimento técnico não é pesquisa científica!}

Minhas primeiras publicações foram sobre os sistemas computacionais que desenvolvi durante minha Iniciação Científica no Bacharelado em Informática na década de 1990, ainda na infância do SBIE (cuja primeira edição foi em 1990) e do WIE (primeira edição em 1995). Devo confessar que, hoje, percebo minhas pesquisas daquela década como sendo do tipo "fiz algo novo, eis meu produto", conforme caracterizado por Wazlawick (2008). Concordando com esse autor, percebo que meus artigos eram parecidos com uma propaganda do produto desenvolvido. Naquela época, fazer pesquisa em Informática na Educação era, para mim, conceber produtos computacionais considerando as teorias de aprendizagem e desenvolver uma "prova de conceito" para mostrar que a proposta era implementável, e isso era suficiente para a comunidade considerar a pesquisa publicável.

Uma prova de conceito, ou PoC (sigla do inglês, Proof of Concept) é um termo utilizado para denominar um modelo prático que possa provar o conceito (teórico) estabelecido por uma pesquisa ou artigo técnico. Pode ser considerado também uma implementação, em geral resumida ou incompleta, de um método ou de uma ideia, realizada com o propósito de verificar que o conceito ou teoria em questão é suscetível de ser explorado de uma maneira útil. ("Prova de Conceito", n.d.)

No primeiro artigo que publiquei no SBIE (Pimentel \& Souza, 1996), apresentei um sistema computacional para apoiar o aprendizado de Algoritmos e Grafos, em que o estudante desenhava um grafo e o sistema apresentava uma animação sobre o desenho para mostrar a aplicação do algoritmo de Busca em Profundidade, e outros algoritmos, disponibilizando também um hipertexto sobre os conteúdos da disciplina: "Esse ambiente é a associação de um laboratório de algoritmos com um hipertexto da matéria" (p.15). Naquele artigo, apresentamos várias telas justificando as "bases pedagógicas do projeto" de acordo com os estudos em psicopedagogia mais difundidos em nossa comunidade: "O programa aceita interações onde o erro é permitido, de forma que o aluno tenha condições de identificar a falha cometida por si mesmo ou através da assistência do computador (Papert, 1985)" (p.17).

Já no primeiro artigo que publiquei no WIE (Pimentel, 1998), apresentei o software educacional "Brincando de Geometria com Caco e Bia" que estava desenvolvendo para o meu Trabalho de Conclusão de Curso em Informática. Havia implementado alguns jogos interativos (Figuras 1.a, 1.b e 1.c) integrados a um hipertexto (Figura 1.d). Muito orgulhoso do software que havia desenvolvido, apresentei algumas das telas que havia criado com muito capricho e justificava minhas escolhas argumentando como aquele produto era lúdico e estava alinhado aos princípios construtivistas:

$\mathrm{Na}$ seção de atividades encontram-se ambientes interativos tais como "Liga Pontos", "Tangram", "Tetris", "Maquetes", "Vistas" etc. Durante a interação com tais ambientes, espera-se que a criança sinta vontade de compreender alguns conceitos formais de geometria, podendo então navegar para a sessão de "conceitos". Nessa seção estão as páginas que abordam sistematicamente o conteúdo de geometria. Cada conceito é ilustrado com as personagens Caco e Bia em uma situação lúdica. (...) Após algum tempo de uso do hipertexto "Brincando de Geometria, com Caco e Bia", as crianças descobrem que aprender geometria pode ser uma divertida brincadeira. (p.631) 


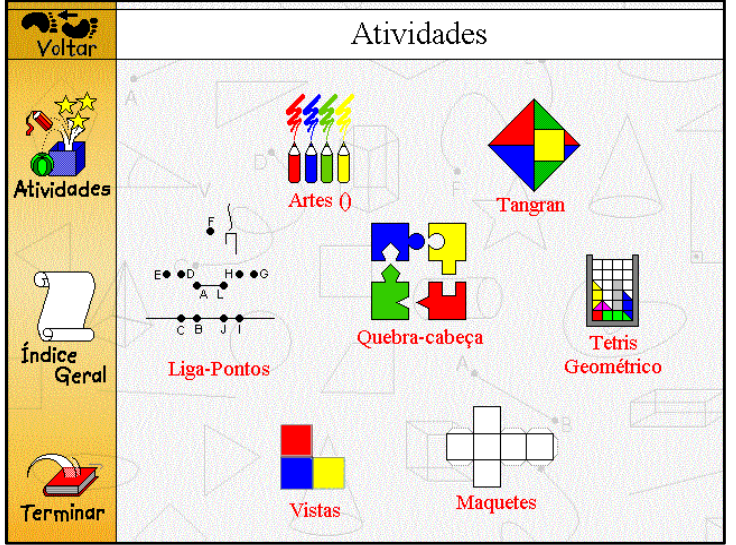

(a)

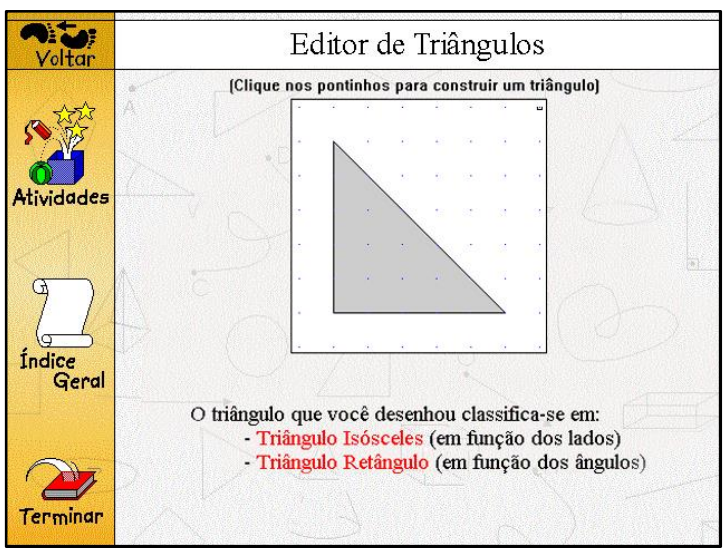

(c)

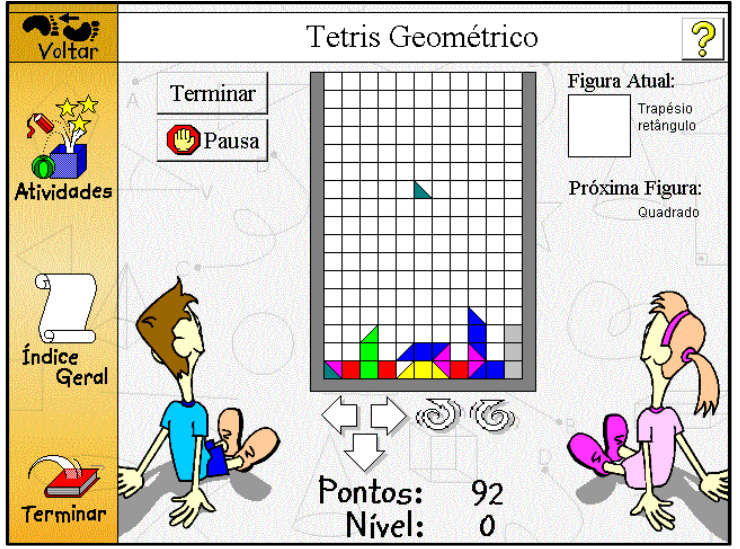

(b)

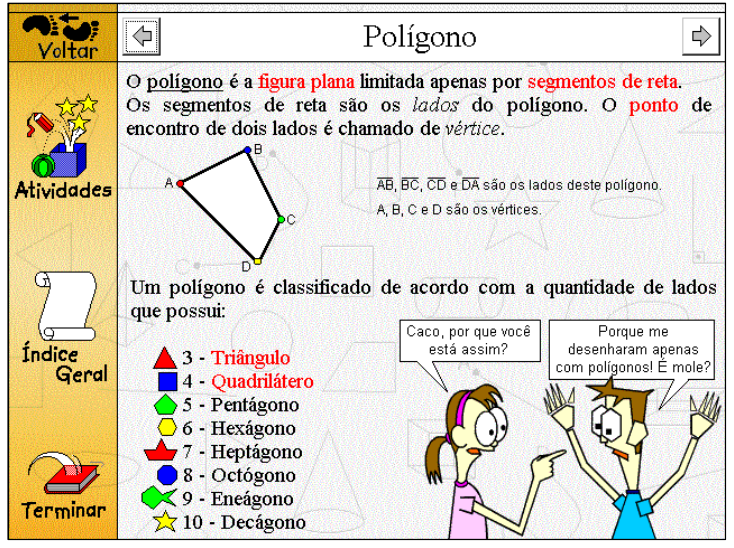

(d)

Figura 1: Software educacional "Brincando de Geometria com Caco e Bia" (Pimentel, 1998).

Custei a compreender que desenvolver sistemas computacionais não é fazer pesquisa científica. Uma incompreensão também apoiada pela maneira como os eventos e periódico de nossa comunidade são apresentados: "O SBIE prioriza trabalhos que apresentem a concepção, o desenvolvimento e a avaliação de soluções das Tecnologias Digitais da Informação e da Comunicação para promoção da aprendizagem" ("XXVIII SBIE", 2017); "Os principais objetivos da revista são: (...) divulgar produtos de Informática aplicáveis à educação" ("Revista Brasileira de Informática na Educação", n.d.).

Essa confusão entre desenvolver um artefato e fazer uma pesquisa científica me perseguiu por muitos anos. Uma confusão que assombra muitos pesquisadores em computação:

Em computação, os termos ciência e tecnologia quase sempre andam tão juntos que muitas pessoas têm dificuldade em distingui-los. (...) Observa-se que, algumas vezes, dissertações e teses em computação, bem como artigos científicos, ainda são fortemente caracterizados como apresentações meramente tecnológicas: sistemas, protótipos, frameworks, arquiteturas, modelos, processos, todas essas construções são técnicas, e não necessariamente ciência. (Wazlawick, 2008)

Devo alertar que esta ainda é uma questão mal resolvida em nossa comunidade. Valores e expectativas da década de 1990 ainda ecoam na contemporaneidade, como revela este comentário de um revisor ao avaliar um artigo que submeti ao SBIE de 2017, em que resumi o presente texto na expectativa de conversar com a comunidade sobre estas minhas reflexões e posicionamentos sobre a práxis científica de nossa comunidade:

Criativo e diferente, com boas discussões. Mas tenho dúvidas sobre a adequação do texto e suas discussões ao evento em questão. (...) Acho que 
deveria haver um espaço para discussões deste teor no CBIE, mas seria o SBIE, o evento mais técnico do CBIE esse lugar?

"SBIE, o evento mais técnico do CBIE". Esta declaração me faz pensar sobre a cultura que ainda existe em nossa área, que ainda há uma expectativa de que esse evento científico esteja focado em aspectos técnicos. Para mim, conforme argumentei nesta seção, o desenvolvimento técnico não caracteriza o fazer científico. Essa confusão entre o fazer científico e o desenvolvimento técnico se transformou em um dilema que busquei compreender ao longo de toda a minha formação e carreira enquanto pesquisador-orientador, e com o presente artigo relato como venho enfrentando tal questão.

\section{Método de Pesquisa Científica: parecia ser a resposta definitiva...}

Foi no início da década de 2000, já cursando o mestrado, que compreendi a noção de pesquisa aplicada e empírica. Naquela época, a Internet estava se popularizando e em nossa área proliferavam as pesquisas voltadas para o desenvolvimento das tecnologias digitais em rede, com especial interesse para a educação a distância e os ambientes virtuais de aprendizagem como TeleEduc e AulaNet, e posteriormente o Moodle. Em 2000, cursei pela primeira vez uma disciplina a distância, intitulada "Tecnologia de Informação Aplicada a Educação (TIAE)" (Fuks, Gerosa \& Lucena, 2001). Fiquei muito impactado especialmente com a ênfase na discussão e na autoria, o que contrastava com as aulas predominantemente expositivas que eu estava acostumado na modalidade presencial. Gostava especialmente das sessões de bate-papo que realizávamos semanalmente naquela disciplina. Como monografia de conclusão da disciplina, discuti a dificuldade que eu sentia em acompanhar a conversação no bate-papo, e discuti, especificamente, um fenômeno que batizei de "perda de co-texto". Havia identificado um problema! Um problema sobre o qual me debrucei no mestrado e por toda a minha carreira posterior enquanto pesquisador-orientador, pois reconheci no bate-papo um meio para promover colaboração, interatividade, diálogo, autoria, emoção e sentimento de pertença, que considero importantes em nossa educação, não somente na educação a distância e online. Quando me deparei com esta famosa citação de Karl Popper, minha "obsessão" por aquele problema passou a fazer sentido para mim:

Penso que só há um caminho para a ciência ou para a filosofia: encontrar um problema, ver a sua beleza e apaixonar-se por ele; casar e viver feliz com ele até que a morte vos separe a não ser que encontrem um outro problema ainda mais fascinante, ou, evidentemente, a não ser que obtenham uma solução. Mas, mesmo que obtenham uma solução, poderão então descobrir, para vosso deleite, a existência de toda uma família de problemas-filhos, encantadores ainda que talvez difíceis, para cujo bem-estar poderão trabalhar, com um sentido, até ao fim dos vossos dias. (Popper, 1989, no exórdio da obra)

Debrucei-me sobre os registros de bate-papo para caracterizar a frequência do problema, contabilizando as manifestações de "perda de co-texto" identificadas ao longo das 13 sessões de bate-papo realizadas naquela disciplina. Cheguei a desenvolver um método de análise do registro de bate-papo com base em técnicas da Análise da Conversação e Análise do Discurso (e hoje, revendo o artigo, reconheço o uso de técnicas de Análise de Redes Sociais que, na época, não conhecia), que publiquei no SBIE (Sampaio \& Pimentel, 2000) e que me rendeu o prêmio de $3^{\circ}$ melhor artigo, que, por sua vez, resultou num convite para a submissão de uma versão estendida do artigo na RBIE (Pimentel \& Sampaio, 2002), meu primeiro artigo publicado em um periódico. Propus uma solução para o problema: encadear as mensagens no bate-papo tal como já fazíamos nos fóruns de discussão, em que o usuário explicita qual mensagem está respondendo, pois sabia que ninguém se perderia na conversação se todas as mensagens estivessem encadeadas. Desenvolvi o sistema de bate-papo "HiperDiálogo" como Prova de 
Conceito (Pimentel \& Sampaio, 2001), para mostrar que a solução proposta era implementável, que era possível associar as mensagens de um bate-papo.

Neste ponto, pensava que já estava com tudo pronto para escrever e defender a dissertação. Contrariando minhas expectativas, meu orientador explicou que ainda era preciso testar o sistema implementado, verificar se a solução proposta realmente resolveria o problema, e investigar o que os usuários achariam do sistema. Ele estava me ensinando o Empirismo:

Por 'existência real' Locke entende a existência independente do pensamento; e por 'existência ideal', a existência na mente. O raciocínio que vai da existência ideal para a real nunca é válido [de acordo com a corrente filosófica empírica]; para mostrar que algo é real, temos que experimentá-lo ou inferi-lo de algo que experimentamos. (...) O empirismo também pode ser expresso como o ponto de vista segundo o qual toda justificação de crenças sobre a existência real depende da experiência, ou seja, é empírica. (...) Para algo ser real deve existir independentemente do que qualquer pessoa pensa a respeito ou, como colocam os escolásticos, de qualquer consideração intelectual, ao passo que a existência ideal é a existência apenas no pensamento. (Meyers, 2017)

A cobrança pela realização de uma experiência com o sistema HiperDiálogo me custou mais um ano de pesquisa. Criamos uma disciplina para podermos experienciar o sistema por algumas semanas, de forma semelhante à disciplina TIAE que eu havia cursado a distância. Para minha surpresa, algumas manifestações do problema ainda ocorreram apesar do uso do mecanismo de encadeamento entre mensagens. Constatei que minha idealização estava equivocada. Tive que investir alguns meses analisando $\mathrm{e}$ interpretando os dados qualitativamente para tentar explicar porque o problema ainda ocorria. Pude identificar a emergência de novos fenômenos decorrentes do uso do sistema, como a modificação da escrita e também da leitura das mensagens de bate-papo. Naquela pesquisa, havia realizado uma sessão de bate-papo com os estudantes para que eles falassem sobre o sistema experienciado; naquela época, eu não sabia que aquela conversa se caracterizava na técnica de pesquisa "grupo focal" para a produção de dados. Também não sabia dizer se o que eu havia feito era um Experimento, um Estudo de Caso ou outra coisa, e, para fugir dessas classificações, disse apenas que havia feito uma "Avaliação" do sistema implementado. Saí pela tangente, mas estava ciente de que precisaria estudar mais sobre como fazer pesquisa científica. Apesar de minhas limitações, aquele trabalho me rendeu o prêmio de melhor dissertação no SBIE de 2002.

Em 2002, comecei o doutorado. Fui estudar com o grupo que desenvolvia o AulaNet e que usava a disciplina TIAE para avaliar suas inventividades. Havia me encantado com aquela abordagem de pesquisa e decidido que gostaria de realizar minhas pesquisas daquela maneira. Para minha surpresa, no curso de doutorado não encontrei uma disciplina específica para discutir o fazer científico. Depois constatei que muitos cursos de pós-graduação em Computação não ofertam disciplinas sobre Metodologia, Epistemologia, Filosofia e História da Ciência. Minha dificuldade não era pessoal; naquela época, havia pouca discussão sobre como fazer pesquisa científica em computação, ao menos sobre o tipo de pesquisa que eu havia me proposto a realizar. Estava fazendo o doutorado em um programa de pós-graduação em Ciência da Computação, que se caracteriza predominantemente como uma ciência formal; nosso grupo de pesquisa era meio estranho àquele programa, pois fazíamos pesquisa em Informática na Educação que requer pesquisa empírica e que se aproxima mais da práxis das ciências sociais:

Um dos critérios de classificação das ciências mais conhecido é o que distingue as ciências em formais e empíricas. (...) As ciências formais, então, estudam as ideias independentemente de sua aplicação à natureza ou ao ser humano (..) o objeto de estudo dessas ciências está na forma, ou seja, nos processos puramente lógicos ou matemáticos. (...) As ciências empíricas são também chamadas, por vezes, de ciências reais ou factuais. Elas estudam os fenômenos 
que ocorrem no mundo real e que, portanto, não são meramente formais. Obrigatoriamente devem fazer uso de observações para fundamentar suas descobertas. (...) As ciências empíricas ainda podem ser divididas em dois grupos: aquelas que estudam a natureza, ou ciências naturais, e aquelas que estudam o ser humano e suas interações, ou ciências sociais. (...) As ciências sociais estudam os aspectos das relações humanas, ou seja, da vida social dos indivíduos. (...) As subáreas da computação mais próximas das ciências sociais são a engenharia de software, a informática na educação, os sistemas de comércio eletrônico (...) etc. (Wazlawick, 2008)

Por indicação de um colega de doutorado, fui fazer uma disciplina com Ana Maria Nicolaci-da-Costa, professora do Departamento de Psicologia, uma pesquisadora que produzia artigos que sobre o uso das tecnologias computacionais. Ela ensinava a realizar pesquisas com base em entrevistas seguindo o método que ela estava desenvolvendo, denominado Método de Explicitação do Discurso Subjacente - MEDS (Nicolaci-da-Costa, 2007). Foi uma disciplina muito perturbadora para mim, pois falava de pesquisas qualitativas e de subjetividade. Guardo uma lembrança que me marcou profundamente: fui conversar com a Ana sobre a pesquisa que estava projetando como trabalho final da disciplina, e apresentei minhas hipóteses sobre a confusão na conversação que gostaria de investigar. Ela, muito firmemente, explicou que, se eu fosse a campo com hipóteses a serem confirmadas ou refutadas, eu já teria estragado toda a pesquisa exploratória; que a abordagem dela requer que o pesquisador não tenha hipóteses préformuladas para que consiga escutar genuinamente o que as pessoas têm a dizer sobre o objeto de pesquisa. Não ter hipóteses? O que ela me pedia era contrário às minhas práticas de pesquisa até então. Confuso e angustiado, sem entender direito como fazer aquele tipo de pesquisa, meus olhos marejaram - aquela angústia marcou uma virada em mim. Refeito, nas aulas seguintes fui compreendendo o que deveria fazer. Refiz meu roteiro de entrevista semiestruturado sobre o uso de bate-papo na educação, depois realizei uma entrevista-piloto para avaliarmos o roteiro, depois das revisões, entrevistei os alunos de uma turma da disciplina a distância TIAE, analisei e interpretei os discursos produzidos nas entrevistas, e publiquei os resultados no WIE (Pimentel, Fuks \& Lucena, 2003), meu primeiro artigo em que havia investigado a subjetividade. Fiquei encantado com o poder de investigação que aquela técnica havia me proporcionado: pela primeira vez pude conversar em profundidade com os usuários e produzir conhecimento sem ficar medindo coisas.

Defendi minha tese de doutorado com tudo ainda meio confuso em mim: já conhecia alguns métodos de pesquisa sem, contudo, dominar nenhum com proficiência; misturava ainda objetividade e subjetividade, pesquisa quantitativa e qualitativa. Hoje reconheço que o relato da tese (e algumas das pesquisas que realizei-orientei posteriormente) refletiu minhas confusões metodológicas. Apesar das limitações, aquele trabalho me rendeu o prêmio de melhor tese de doutorado no SBSI (Simpósio Brasileiro de Sistemas de Informação) de 2006 (Pimentel, 2006).

Poucos meses depois de meu doutoramento, passei num concurso e ingressei na UNIRIO, universidade em que trabalho até hoje. Meu concurso foi para lecionar Informática na Educação em um curso de Bacharelado em Sistemas de Informação. Em 2007, iniciamos a primeira turma de mestrado do nosso Programa de Pós-Graduação em Informática com ênfase em Sistemas de Informação. Estava me sentindo em casa: não mais Ciência da Computação, mas sim Sistemas de Informação:

Sistemas de Informação representam agentes fundamentais da transformação social contemporânea, requerendo entendimento dos contextos sociais e suas relações onde serão utilizados e da influência que as características do ambiente, bem como características individuais e de comportamento dos agentes sociais humanos nestes contextos exercem no uso e no projeto destes sistemas. ("Referenciais de Formação para os Cursos de Graduação em Computação 2017”, 2017). 
Enquanto professor-pesquisador-orientador de pesquisas em Sistemas de Informação, senti necessidade de superar urgentemente minhas limitações em metodologia de pesquisa científica. Estudei em mais profundidade, e pratiquei junto com os mestrandos que começava a orientar, o método Estudo de Caso (Yin, 2005; Pimentel, 2011) e também Experimento (Wainer, 2007, 2011). Também aprendi Pesquisa-ação (Filippo, 2011) ao apoiar uma amiga em sua tese no mesmo grupo onde havia me doutorado. Numa banca em que participei em meu programa de pós-graduação, pude conhecer mais sobre Netnografia; em outra, aprendi mais sobre Survey; e assim fui me formando melhor.

Considero que foi na década de 2000 que ampliei e consolidei meu repertório de métodos de pesquisa, desenvolvendo competências para realizar e orientar pesquisas em Sistemas de Informação e em Informática na Educação. Acreditando nisso, até comecei a escrever sobre Metodologia de Pesquisa Científica (Filippo, Pimentel \& Wainer, 2011). Nessa mesma década, acompanhei o amadurecimento do SBIE e do WIE com a crescente cobrança de que os artigos apresentassem estudos empíricos com o emprego de algum método de pesquisa científica. Hoje, nas chamadas para a submissão de artigos nesses eventos, está explicitado: "Os trabalhos devem demonstrar a qualidade acadêmica avaliada pela solidez da metodologia utilizada" ("XXVIII SBIE", 2017).

Estava em paz achando que já sabia orientar pesquisas com rigor científico, até que...

\section{Design Science Research: finalmente uma epistemologia para produzir conhecimento científico por meio do desenvolvimento de artefatos}

No início da década de 2010, Flávia Santoro, uma colega pesquisadora, ao retornar de seu pósdoutorado em Sistemas de Informação no exterior, apresentou-me a abordagem epistemológicametodológica Design Science Research - DSR (Dresch, Lacerda \& Antunes, 2015). Ela relatou que essa abordagem estava se popularizado muito na área de Sistemas de Informação. Imediatamente compreendi o porquê: é uma abordagem que legitima o desenvolvimento de artefatos como um meio para se produzir conhecimento científico do ponto de vista epistemológico e filosófico, principalmente a partir da obra de Hebert Simon (1969) sobre as Ciências do Artificial. Sabemos que os métodos de pesquisa tradicionalmente usados em computação, notadamente Experimento, Estudo de Caso e Survey, não pressupõem o desenvolvimento de um artefato no contexto da pesquisa; entretanto, nas teses e dissertações em computação, frequentemente aparece um capítulo sobre um artefato desenvolvido, o que não dialoga com o método de pesquisa, o que gera muitas dúvidas nos pesquisadores. Nesse sentido, finalmente havia encontrado uma abordagem que resolvia meu dilema em inter-relacionar o desenvolvimento técnico e o científico.

É da cultura de nossa área realizar pesquisas que incluem o desenvolvimento de algum artefato: sistema computacional, método, processo, modelo, arquitetura, dispositivo eletrônico etc. $\mathrm{Eu}$, particularmente, venho trabalhando focado no desenvolvimento de sistemas computacionais para apoiar o uso de bate-papo online na educação. Alerto os pós-graduandos, contudo, que o objetivo não pode ser apenas o desenvolvimento do artefato. Enquanto cientistas, precisamos produzir conhecimento e não apenas uma tecnologia:

O objetivo da pesquisa em sistemas de informação é produzir conhecimento e compreensão que possibilitem o desenvolvimento e implementação de soluções baseadas em tecnologias para problemas de negócios importantes e ainda não resolvidos (Hevner, March, Park \& Ram, 2004).

Na Figura 2 apresento o mapa que elaborei, com base em Wieringa (2014) e Hevner e Chatterjee (2010), para explicar quais são os principais elementos de uma pesquisa em DSR. 
Nessa abordagem, um artefato é projetado para resolver algum problema num dado contexto a partir de conhecimentos e conjecturas sobre o mundo; e o uso do artefato, por sua vez, é o que possibilita avaliar as conjecturas elaboradas, o que nos possibilita produzir conhecimento sobre o mundo (ciência).

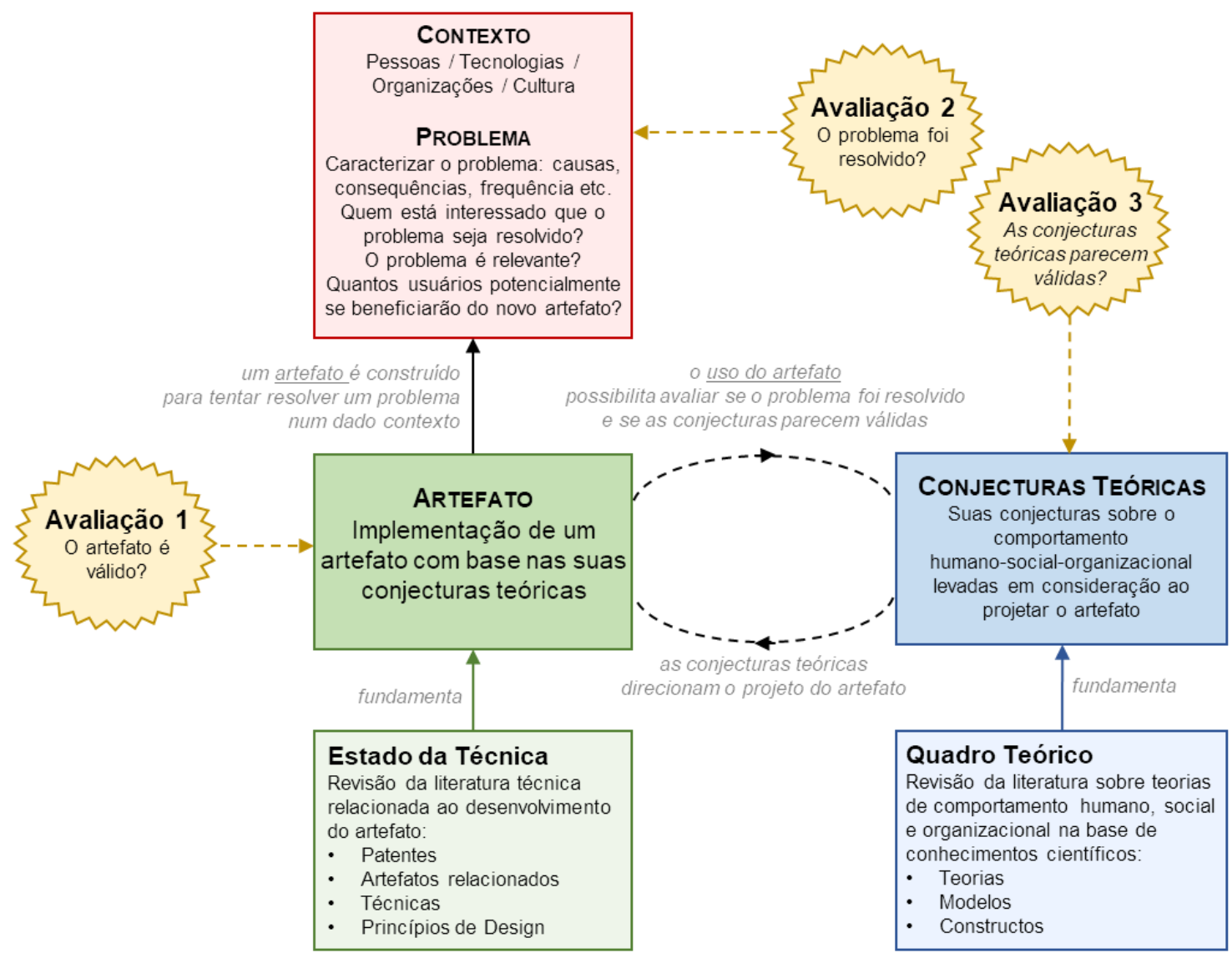

Figura 2: Mapa dos elementos que caracterizam uma pesquisa em DSR.

Desenvolver um artefato não requer apenas conhecimento técnico. Um artefato é projetado a partir de pressuposições sobre como as pessoas agem num dado contexto, como uma organização funciona, quais são suas práticas e cultura. Ao explicitarmos as conjecturas teóricas que direcionam o projeto do artefato, estamos teorizando sobre essas coisas. A teorização precisa dialogar com a base de conhecimento científico, com teorias que geralmente não estão na Ciência da Computação (predominantemente formal e técnica), mas sim na Educação, Psicologia, Sociologia, Filosofia, Linguística, Administração, Marketing dentre outras áreas. Explicitar o quadro teórico que fundamenta as conjecturas consideradas no projeto de um artefato garante o rigor teórico requerido das pesquisas científicas. Com essa separação entre o projeto do artefato e as conjecturas teóricas, ficou mais evidente para o nosso grupo de pesquisa que precisamos revisar a literatura com duas finalidades: para caracterizar o estado da técnica (conhecimento técnico) e para construir um quadro teórico (conhecimento científico). Nas pesquisas que orientei antes de DSR, não diferenciava muito bem o estado da técnica e o quadro teórico, tudo ficava meio misturado em nossos relatos numa única seção sobre Revisão de Literatura. Como resultado dessa confusão, nem sempre em nossas pesquisas apresentávamos um quadro teórico adequado. Estruturar a pesquisa de acordo com o mapa apresentado na Figura 2 tem ajudado nosso grupo a diferenciar os propósitos da revisão de literatura e a compreender que precisamos teorizar em nossas pesquisas.

Antes de me apropriar de DSR, nas pesquisas que orientei e realizei, muitas vezes investigava apenas se o artefato era válido (Avaliação 1 da Figura 2), por exemplo, por meio de 
um teste de usabilidade do sistema ou por meio de uma investigação se usuários em potencial compreendem o artefato proposto. Eventualmente conseguíamos investigar também se o artefato diminuía o problema no contexto real para o qual havia sido projetado (Avaliação 2 da Figura 2) - por exemplo, na pesquisa que publicamos no SBIE de 2008 (Nunes, Barbosa \& Pimentel, 2008), investigamos se os mecanismos que propusemos e implementamos num dado sistema de bate-papo diminuiriam o problema de perguntas que ficam sem ser respondidas durante uma sessão de bate-papo (problema investigado) e realizamos uma avaliação por meio de um Estudo de Caso numa perspectiva epistemológica que hoje reconheço como Positivista, ainda que tenhamos trabalhado também com dados qualitativos. Achava, realmente, que era suficiente investigar se o artefato resolvia o problema. Hoje reconheço que aquela foi uma pesquisa aplicada, com um desenvolvimento técnico interessante, com um bom estudo piloto e boa pesquisa de campo; contudo, não avançamos muito em termos teóricos, ou ao menos não realizamos o exercício de reflexão sobre as conjecturas que havíamos feito e de outras contribuições para o corpo de conhecimento teórico (Avaliação 3 da Figura 2). DSR nos explicitou que não é suficiente apenas avaliar a validade do artefato proposto; é preciso também investigar se o artefato realmente resolve o problema no contexto em questão; e mais que isso, é preciso também produzir conhecimento teórico, investigar as conjecturas elaboradas e avançar com o conhecimento científico que fundamentou a pesquisa. A abordagem DSR complexificou nossas pesquisas; por outro lado, passei a ter mais segurança de estar fazendo uma pesquisa que reconheço como científica, e não apenas um desenvolvimento técnico.

Após os primeiros trabalhos em que ainda estávamos aprendendo a operacionalizar a abordagem DSR em nossas pesquisas, foi com a dissertação do Thiago Marcondes Santos que conseguimos resultados mais alinhados ao modo DSR de produzir conhecimento. Publicamos essa pesquisa no WIE (Santos, Filippo \& Pimentel, 2015), que nos rendeu prêmio de melhor artigo e um convite para submetermos uma versão expandida para a revista RBIE (Santos, Pimentel \& Filippo, 2016). Publicamos também essa pesquisa em uma revista da área de Educação (Pimentel, Filippo \& Santos, 2015). Essa pesquisa também nos rendeu o prêmio de melhor dissertação de Informática na Educação no SBIE de 2016. Ficamos entusiasmados com o reconhecimento, ainda mais porque havíamos realizado uma pesquisa com perspectiva Interpretativa, tendo o pesquisador atuado como um participante realizando observação direta, grupo focal e entrevistas com os sujeitos envolvidos no estudo de campo feito em escolas públicas (contexto real). O prêmio nos surpreendeu e mostrou que a área estava receptiva também para outras abordagens epistemológicas-metodológicas para além do Positivismo. Não paramos mais... agora, quase todas as pesquisas do grupo são pensadas na perspectiva epistemológica DSR, como exemplificam as posteriores dissertações da Valleska (Silva, Pimentel \& Dias, 2015) e do Adilson (Silva, 2016).

Quero aqui assumir que "Epistemologia" era um conceito difícil para mim; todas as vezes que lia nos livros ou na internet, não compreendia muito bem a diferença entre Epistemologia e Método de Pesquisa. Tudo começou a fazer mais sentido quando aprofundei meus estudos e consegui compreender que DSR se tratava, de fato, de uma epistemologia: um modo de pensar a produção de conhecimento reconhecido por um grupo de pesquisadores. Diferentes métodos de pesquisa foram e ainda estão sendo propostos para sistematizar um conjunto de passos para se produzir conhecimento a partir dessa perspectiva epistemológica, como exemplifica o método DSRM (Peffers, Tuunanen, Rothenberger \& Chatterjee, 2008) que temos adotado em nosso grupo de pesquisa. O quadro que apresento na Tabela 1, elaborado com base em Vaishnavi e Kuechler (2015) no qual acrescentei a linha correlacionando os métodos de pesquisa, tem me ajudado a compreender, diferenciar e explicar esses conceitos: 
Tabela 1: Comparações entre os diferentes (meta)paradigmas de pesquisa [baseado em (Vaishnavi \& Kuechler, 2015)].

\begin{tabular}{|l|l|l|l|}
\cline { 2 - 4 } \multicolumn{1}{c|}{} & \multicolumn{3}{c|}{ Perspectivas de Pesquisa } \\
\hline Crença Básica & \multicolumn{1}{|c|}{ Positivista } & \multicolumn{1}{c|}{ Interpretativa } & \multicolumn{1}{c|}{ Pragmática/Projeto (Design) } \\
\hline Ontologia & $\begin{array}{l}\text { Uma única realidade. } \\
\text { Conhecível, probabilística }\end{array}$ & $\begin{array}{l}\text { Múltiplas realidades, } \\
\text { socialmente construídas }\end{array}$ & $\begin{array}{l}\text { Múltiplas alternativas de estados do } \\
\text { mundo, contextualmente situadas, } \\
\text { possibilitadas socio-tecnicamente. }\end{array}$ \\
\hline $\begin{array}{l}\text { Axiologia: qual é } \\
\text { o valor (ética) }\end{array}$ & $\begin{array}{l}\text { Verdade: universal e } \\
\text { bonita; predição }\end{array}$ & $\begin{array}{l}\text { Compreensão: situada e } \\
\text { descrição. }\end{array}$ & $\begin{array}{l}\text { Controle; criação; progresso (melhoria, } \\
\text { aperfeiçoamento); compreensão. }\end{array}$ \\
\hline $\begin{array}{l}\text { Eétodos de } \\
\text { Pesquisa }\end{array}$ & $\begin{array}{l}\text { Objetiva, imparcial. } \\
\text { Observador separado da } \\
\text { verdade (neutro) } \\
\text { Testes de IHC }\end{array}$ & $\begin{array}{l}\text { Subjetiva, i.e., valores e } \\
\text { conhecimento emergem da } \\
\text { parteração pesquisador- }\end{array}$ & $\begin{array}{l}\text { Conhecimento pelo fazer: construção } \\
\text { objetivamente restrita dentro de um } \\
\text { contexto. A circunscrição iterativa } \\
\text { revela significados. }\end{array}$ \\
\hline Experimento; Survey; & Etnografia & $\begin{array}{l}\text { ESRM (Peffers et al., 2008); Pesquisa- } \\
\text { ação }\end{array}$ \\
\hline
\end{tabular}

DSR, assim como Pesquisa-ação e outras abordagens de pesquisa-intervenção, podem ser reconhecidas como filiadas ao meta-paradigma epistemológico Projetivo, em que se faz ao mesmo tempo pesquisa e ação com o objetivo de mudar a realidade (projetá-la), e não apenas tentar compreendê-la e explicá-la. É o caminho político que escolhi na expectativa de fazer pesquisas em informática que sejam úteis para a educação.

Tornar nossas pesquisas úteis, ainda é um desafio que nosso grupo de pesquisa vem enfrentando. Os artefatos que temos desenvolvido, em geral são protótipos que acabam sendo desativados após a defesa da pesquisa. Mais recentemente, com a homologação do curso de Doutorado em nosso programa de pesquisa, temos investido esforços para superar a geração de protótipos descartáveis em busca da construção de um produto que perpasse e sobreviva às pesquisas individuais dos membros de nosso grupo de pesquisa. Cobiçamos desenvolver, como produto, uma Rede Social de Bate-papo para Educação (Pimentel, 2017). Esse enfoque no desenvolvimento do artefato é o que diferencia DSR da Pesquisa-ação, que se volta mais para a intervenção em uma comunidade (Lima, Oliveira, Fialho, Deusdara \& Barros Neto, 2014).

\section{Pesquisas com os Cotidianos Escolares: adeus ao Positivismo...}

Foi também durante a década de 2010, em função da interatividade que vinha estabelecendo com os pesquisadores da linha "Cotidianos, Redes Educativas e Processos Culturais" do programa de pós-graduação em Educação da UERJ (nota 7 na CAPES), que conheci a epistemologia das Pesquisas nos/dos/com os Cotidianos em Educação, que tem influenciado diversos pesquisadores em Educação no Brasil (Alves, 2001, 2008; Soares, 2013; Ferraço, Soares \& Alves, 2017).

Não posso dizer que foi amor à primeira vista; foi desconcertante. Convidado para compor a banca de mestrado da Raquel Colacique (2013), orientada por minha colega de profissão Edméa Santos (2015), com quem já vinha trabalhando desde 2007 (pois ambos atuamos na disciplina Informática na Educação do curso de Licenciatura em Pedagogia a Distância, só que ela pela UERJ e eu pela UNIRIO, pois o curso é ofertado por diferentes instituições vinculadas ao CEDERJ/UAB), ao ler a dissertação da mestranda, cheguei ao ponto 
de chorar. Fiquei aturdido com as narrativas sensíveis que estava lendo naquela dissertação. Não sabia que um relato de pesquisa científica poderia me emocionar. Quem disse que não podia?

As dissertações e teses em computação são quase todas impessoais, com uso e abuso de orações com sujeito indeterminado e da voz passiva, empregando uma linguagem tão impessoal que impede o leitor perceber o autor por trás do texto - recursos linguísticos para fazer o leitor acreditar em verdades objetivas, absolutas e independentes do pesquisador (Becker, 2015), que pretensamente se posiciona como neutro e sem envolvimento emocional com seu objeto de estudo, que não participa para não "contaminar" o estudo, e essa postura também se reflete no estilo linguístico da escritura retirando do texto a voz do pesquisador. Aquela dissertação da Raquel, no campo da Educação, era muito diferente de tudo a que estava acostumado na computação. Naquele relato, a pesquisadora explicitava sua implicação com o tema, sua militância, sua intencionalidade com aquela pesquisa, de que posição política-ética-estéticateórica-epistemológica-metodológica estava produzindo conhecimento, e com aquelas informações eu conseguia compreender melhor o relato da pesquisa.

Participei de outras bancas na Educação, mas foi a tese de Rosemary Santos (2015) que despertou, em mim, a cobiça de ser capaz de produzir conhecimento ao modo Cotidianista. Naquela época, estava começando a orientar alunos de doutorado, estava mais alerta para o modo como poderia vir a orientar as pesquisas no grupo que coordeno. Desde então venho estudando a literatura e participando de aulas de pesquisadores que atuam na linha de pesquisas com os cotidianos escolares. Também venho trabalhando os pressupostos teóricosepistemológicos-metodológicos dessa linha com o grupo de pesquisa que coordeno. Temos buscado inventar um modo de fazerpensar as pesquisas em Informática na Educação considerando que estamos num programa de Computação.

A epistemologia das pesquisas com os cotidianos escolares está fundada nos estudos do cotidiano de Michel de Certeau (1994) articulados com a noção de redes de conhecimentos e significações nos cotidianos proposta por Lefebvre (1983). Nilda Alves $(2001,2008)$ propôs 5 movimentos que os pesquisadores devem realizar ao fazerpensar as pesquisas com os cotidianos escolares, o que vem movimentando nosso grupo de pesquisa desde meados da década de 2010.

O primeiro movimento é denominado "sentir o mundo", que indica que o pesquisador precisa mergulhar no cotidiano escolar com todos os sentidos. Nessa abordagem, o pesquisador não realiza estudos em laboratórios, não investiga o uso do artefato por meio de testes controlados para a realização de tarefas artificiais como tipicamente se pratica em nossa área ainda predominantemente positivista. $\mathrm{O}$ que essa abordagem propõe é que o pesquisador faça um mergulho na realidade do cotidiano escolar vivenciando as experiências na pele, atento ao que dizem e sentem os praticantes, seus valores e práticas culturais. Esse movimento não causou muito estranhamento em nosso grupo de pesquisa, pois já realizávamos Estudos de Caso, em que se pesquisa um fenômeno real no contexto em que ocorre. Contudo, em nosso grupo também realizávamos algumas pesquisas seguindo o método Experimento, em laboratório, com dados quantitativos, tentando controlar, abstrair e generalizar tudo - hoje também considero que a perspectiva Positivista é muito limitadora, como apontado por Nilda Alves (2001, p.13): "Se continuo somente 'olhando do alto', como os que têm poder, vou compreendê-1o [o cotidiano escolar] muito limitadamente, é preciso reconhecer." Por isso, em nosso grupo, resolvemos abraçar a perspectiva Interpretativa, de abordagem subjetiva operacionalizada por etnométodos, e abandonar de vez o Positivismo. Estamos cientes das dificuldades que enfrentaremos em nossa comunidade, pois na Computação o método Experimento ainda é frequentemente apresentado como sendo "o método científico", sendo ignoradas ou invisibilizadas todas as demais epistemologias e métodos. Resolvemos encarar essa dificuldade como uma oportunidade para fazermos diferente e assim fazermos a diferença. 
O segundo movimento é intitulado "Virar de ponta cabeça". Muitas pesquisas partem de teorias que fornecem categorias, conceitos e noções para interpretar os fenômenos. É evidente que nosso repertório teórico nos ajuda a pensar a realidade do cotidiano escolar, mas não devemos reduzir os fenômenos somente àquilo que é explicável pelas categorias prévias. Ao mesmo tempo em que os pressupostos teóricos nos ajudam a interpretar a realidade, eles também limitam nossa capacidade de interpretação, e nem sempre reconhecemos a teoria como uma limitação. Nilda Alves nos alerta que devemos realizar um movimento para nos libertarmos das amarras que um referencial teórico nos impõe. Entendemos esse movimento, em nosso grupo, como uma demanda por teorizarmos mais em nossas pesquisas (o que nem sempre fazíamos) sem, contudo, nos restringirmos às categorias prévias de análise para compreendermos os usos dos artefatos que projetamos em nossas pesquisas. Esse é um princípio que o método MEDS (Nicolaci-da-Costa, 2007) também já havia nos ensinado, pois seguindo aquele método empregamos uma abordagem êmica: os discursos são analisados e interpretados para fazer emergir categorias a partir das falas dos entrevistados.

O terceiro movimento, caracterizado como "beber de todas as fontes", refere-se a apoiarse em múltiplas fontes de dados e conhecimentos para enfrentar a complexidade, a diversidade, a heterogeneidade, a diferença no cotidiano pesquisado. Desse movimento compreendemos, por exemplo, que devemos apresentar as falas dos sujeitos de nossas pesquisas na mesma horizontalidade que as dos teóricos, e não numa relação de subordinação para apenas ilustrar uma categoria teórica prévia. Compreendemos, também, a possibilidade de considerarmos diversas fontes de conhecimento como válidas, numa perspectiva multirreferencial, dialogando com a cultura e não apenas com os conhecimentos reconhecidos como científicos:

a abordagem multirreferencial propõe-se a uma leitura plural de seus objetos (práticos ou teóricos), sob diferentes pontos de vista, que implicam tanto visões específicas quanto linguagens apropriadas às descrições exigidas, em função de sistemas de referências distintos (Ardoino, 1998, p.25)

(...) essa perspectiva epistemológica fala e propõe uma formação que ultrapasse a redução à disciplinarização, aos modelos técnicos e academicistas. A disciplina, mesmo criticamente ressignificada, passa a ser mais uma das referências importantes para tratarmos com as situações e sua inerente pluralidade, e não a única referência. (...) Em vez de se considerar a última fronteira da verdade, ou mais delirante ainda, a própria verdade, irá se satisfazer com a condição de um olhar singular que se tornou histórica e socialmente importante. (...) Nesse movimento se disponibilizará a uma tensão intercrítica, como reconhecimento de que não se faz conhecimento social e culturalmente relevante alijando-se saberes outros. (Macedo, 2012, p. 36-38)

O quarto movimento intitula-se "narrar a vida e literaturizar a ciência". Por "narrar a vida", entendemos a ação de relatar as experiências que o pesquisador vivencia no cotidiano, trazendo para o relato as narrativas, as conversas, as imagens e os sons produzidos nos acontecimentos. Por "literaturizar a ciência", entendemos como um movimento estético de produzir um texto que seja mais prazeroso de ser lido, dialógico e pessoal, assumidamente nãoneutro; e também um movimento político, visando tornar nossos textos acadêmicos mais acessíveis a professores e técnicos que eventualmente se dispuserem a ler nossos relatos. Raquel Colacique (2013) havia narrado belissimamente sua vida e literaturizado o relato de sua pesquisa, o que explica a emoção que senti ao ler aquela dissertação. É esse o movimento que faço no presente artigo ao narrar minha vida e tentar literaturizar a ciência que estou aqui produzindo. 
O quinto movimento, publicado alguns anos depois (Alves, 2008), refere-se à "presença necessária e obrigatória dos praticantespensantes dos cotidianos como seus criadores" (Ferraço et al., 2017, p.16). Em nosso grupo, compreendemos esse movimento como sendo a valorização dos professores e estudantes que fazem uso dos artefatos que projetamos em nossas pesquisas uma opção política e ética. Esse movimento já estava em minha práxis de pesquisa desde a época do mestrado, quando meu orientador solicitou investigar o que os usuários achariam do sistema computacional desenvolvido. Parece óbvio, não? Não, não é. Algumas pesquisas em computação não envolvem os humanos; algumas pesquisas em Informática na Educação também não. Nem sempre os pesquisadores se interessam pelo que professores e alunos têm a dizer sobre o artefato projetado. Em nosso grupo de pesquisa, sempre estivemos atentos para a necessidade de compreendermos os usuários como praticantespensantes combatendo a noção sarcástica e opressora de que "o usuário é burro", muito difundida entre os desenvolvedores de sistemas computacionais. Em nosso grupo de pesquisa, investigamos os usos que alunos e professores fazem dos sistemas computacionais que implementamos, nos importamos com o que esses usuários realmente têm a dizer sobre o artefato desenvolvido. Acho que já havia aprendido isso com o princípio da "livre escuta", que fundamenta o método de entrevista que havia praticado em meu doutoramento.

Percebo, agora, que o modo como fazia pesquisa subjetiva, quando a fazia, aprendida com o método MEDS (Nicolaci-da-Costa, 2007), já estava, de algum modo, alinhado com a abordagem epistemológica das pesquisas com os cotidianos escolares, e talvez também por isso eu estivesse preparado para compreender essa abordagem. Atualmente, em nosso grupo de pesquisa, temos nos apoiado mais na abordagem cotidianista que, por ser específica do campo da Educação, nos fornece pressupostos epistemológicos-metodológicos específicos para investigarmos o uso do artefato pelos estudantes e professores em atividades realizadas no contexto educacional, buscando conhecer não só a opinião desses usuários-praticantes sobre o artefato vivenciado, mas também suas táticas, suas "artes de fazer" próprias, suas apropriações, significações, representações e subjetivações.

\section{Considerações finais: lições aprendidas e alguns encaminhamentos}

Nosso grupo de pesquisa considera que, para criarmos conhecimento relevante sobre os artefatos sociotécnicos que desenvolvemos para o contexto educacional, tem sido importante realizarmos pesquisas com base na abordagem epistemológica-metodológica das Pesquisas com os Cotidianos Escolares bricolada à Design Science Research. Essas abordagens de pesquisa ainda são pouco conhecidas na Computação, em que, mesmo nas pesquisas em Informática na Educação, ainda predomina a abordagem positivista. O que precisamos nos perguntar: é adequado fazer pesquisas sobre informática aplicada à educação do ponto de vista de um laboratório, sem precisar estar efetivamente imerso no cotidiano escolar?

Medições objetivas de uma realidade exterior, embora tenham tido grande êxito na produção do conhecimento e no desenvolvimento de técnicas, podem ser problemáticas quando endereçamos questões que envolvem tecnologia, pessoas e organizações. Diferente de matérias inanimadas, componentes químicos e organismos biológicos, as pessoas muitas vezes não reagem da mesma maneira após a realização de um experimento científico; ou seja, elas aprendem com o experimento e mudam seus comportamentos. Além disso, as pessoas e os sistemas de informação não podem ser facilmente separados do seu contexto para realização de pesquisas em laboratório. Desse modo, as abordagens interpretativas podem ser mais eficazes no sentido de se produzir conhecimento relevante a partir da investigação de sistemas de informação inseridos nas organizações e na sociedade, bem como no contexto educacional. 
Em nosso grupo de pesquisa, aprendemos a investigar o que os usuários acham do sistema experienciado, que sentidos e usos fazem do artefato, como o sistema computacional modifica as práticas dos atores e as relações entre eles, o que precisa melhorar, dentre outros aspectos cuja complexidade não pode ser reduzida a um número. Temos buscado compreender os sistemas computacionais como artefatos sociotécnicos (e não apenas técnicos), usados por professores e alunos num contexto real, e por isso precisamos "fazer com" os usuários para juntos compreendermos o artefato projetado, realizando observação direta e interagindo com as pessoas usando o sistema computacional em suas atividades cotidianas, conversando livremente ou por meio de entrevista ou grupo focal. Torna-se necessário interpretar (em vez de medir) os discursos produzidos pelos usuários e suas ações (registradas em anotações, vídeo ou log do uso do sistema).

À primeira vista, a abordagem Cotidianista pode parecer incompatível com DSR, pois dizem que DSR "tende a ser positivista", como apontado por Lima et al. (2014, p.13). Entendemos, contudo, que essa tendência é decorrente da tradição da área de pesquisa em computação, e não da abordagem epistemológica DSR, pois essa epistemologia pressupõe a produção de conhecimento teórico reconhecido como científico a partir do projeto e do uso de artefatos, mas não estabelece que as avaliações sobre o uso do artefato precisam ser objetivas, quantitativas, fundadas no Positivismo. Além disso, DSR não pressupõe a postura generalizante (para qualquer contexto), abstrata (em laboratório, um simulacro da realidade) e neutra (pesquisador afastado de seu objeto de pesquisa), que são os pressupostos do Positivismo. DSR pressupõe a produção de conhecimentos em contextos específicos (não facilmente generalizáveis) e reais (em vez do laboratório), com base na autoria criatividade do pesquisador que projeta artefatos (em vez da neutralidade). Nosso grupo, em vez de considerar que DSR "tende a ser positivista", questionamos se o Positivismo é compatível com a epistemologia DSR. Compreendemos que a Pesquisa com os Cotidianos Escolares, por exigir o mergulho no cotidiano investigado (contexto), apresenta-se mais alinhada aos pressupostos de DSR, e por isso temos operacionalizado a bricolagem entre essas abordagens nas pesquisas de nosso grupo, o que tem se mostrado adequado para fazerpensar pesquisas rigorosas, úteis e relevantes em Informática na Educação.

Com este artigo, espero ter ressaltado a importância de discutirmos os pressupostos epistemológicos-metodológicos de nossas pesquisas nos relatos submetidos aos eventos científicos e periódicos de nossa área, pois essa discussão tem potencial para aumentar a qualidade e a relevância de nossas pesquisas. Com essa iniciativa, espero contribuir para apoiar nossa comunidade de pesquisadores em computação atuantes em Informática na Educação a entrar na década de 2020 mais amadurecida.

\section{Referências}

Alves, N. (2001). Decifrando o pergaminho - os cotidianos das escolas nas lógicas das redes cotidianas. In I. Oliveira \& N. Alves (Eds.), Pesquisa nos/dos/com os cotidianos das escolas. Petrópolis, RJ: DP\&A.13-38.

Alves, N. (2008). Sobre movimentos das pesquisas nos/dos/com os cotidianos. Em: I. Oliveira \& N. Alves (Ed). Pesquisa nos/dos/com os cotidianos das escolas. Petrópolis/RJ: DP\&A. $39-48$.

Ardoino, J. (1998). Abordagem multirreferencial (plural) das situações educativas e formativas. In J.G. Barbosa (Ed.), Multirreferencialidade nas ciências e na educação (pp. 24-41). São Carlos, SP: UFSCar. 
Becker, H.S. (2015). Truques da escrita: para começar e terminar teses, livros e artigos. Rio de Janeiro: Zahar.

Becker, H. S. (1986). Biographie et mosaïque scientifique. Actes de la Recherche en Sciences Sociais, 62/63, 105-110. [GS Search]

Certeau, M. (1994). A invenção do cotidiano: 1. artes de fazer. Petrópolis, RJ: Vozes.

Colacique, R. (2013). Acessibilidade para surdos, na cibercultura: Os cotidianos nas redes e na educação superior online (Dissertação de Mestrado). ProPEd-UERJ. Retrieved from http://www.proped.pro.br/teses/teses_pdf/2009 1-560-ME.pdf [GS Search]

Dresch, A., Lacerda, D. P., \& Antunes Jr, J. A. V. (2015). Design Science research: método de pesquisa para avanço da ciência e tecnologia. Porto Alegre, Bookman. [GS Search]

Ferraço, C. E., Soares, M. C. S., \& Alves, N. (2017). Michel de Certeau e as pesquisas nos/dos/com os cotidianos em educação no Brasil. Pedagogia y Saberes, 46, Universidad Pedagógica Nacional, Facultad de Educación, p.7-17. [GS Search]

Ferraroti, F. (1983) Histoires et histoires de vie. Paris: Méridiens.

Filippo, D. (2011). Pesquisa-ação em sistemas colaborativos. In M. Pimentel \& H. Fuks (Eds.) Sistemas Colaborativos (capítulo 26). Rio de Janeiro: SBC/Elsevier. Retrieved from https://www.dropbox.com/sh/ftcq79y2aqq16u4/_sFxQwE8iO

Filippo, D., Pimentel, M., \& Wainer, J. (2011). Metodologia de pesquisa científica em sistemas colaborativos. In M. Pimentel \& H. Fuks (Eds.) Sistemas Colaborativos (capítulo 23). Rio de Janeiro: SBC/Elsevier. from https://www.dropbox.com/sh/ftcq79y2aqq16u4/_sFxQwE8iO

Fuks, H., Gerosa, M. A., \& Lucena, C. J. P. (2001). Sobre o desenvolvimento e aplicação de cursos totalmente a distância na Internet. Revista Brasileira de Informática na Educação, 9, 61-75. Retrieved from http://br-ie.org/pub/index.php/rbie/article/view/2238 [GS Search]

Hevner, A. R., March, S. T., Park, J., \& Ram, S. (2004). Design Science in information systems research. MIS Quarterly, 28(1), 75-105. [GS Search]

Hevner, A., Chaterjee, S. (2010) Design Research in Information Systems: theory and practice. Springer. [GS Search]

Lefebvre, H. (1983). Lógica formal - lógica dialética. Rio de Janeiro: Civilização Brasileira.

Lima, S. H. O., Oliveira, F. D., Fialho, K. E. R., Deusdara, D. F. M., \& Barros Neto, J. P. (2014). Design Science: Perspectivas Paradigmáticas e Comparações com Estudo de Caso e Pesquisa-Ação. VII Encontro de Estudos Organizacionais da ANPAD. Gramado - RS: ANPAD. [GS Search]

Macedo, R. S. (2006). Etnopesquisa crítica, etnopesquisa-formação. Brasília: Liber Livro Editora.

Macedo, R. S. (2012). Multirreferencialidade: o pensar de Jacques Ardoino em perspectiva e a problemática da formação. In R. S. Macedo (Ed.) Jacques Ardoino \& a Educação (pp.3562). Belo Horizonte: Autêntica Editora.

Meyers, R. G. (2017). Empirismo. Petrópolis, RJ: Vozes.

Nicolaci-da-Costa, A. M. (2007). O campo da pesquisa qualitativa e o Método de Explicitação do Discurso Subjacente (MEDS). Psicol. Reflex. Crit. [online], 20(1), 65-73. [GS Search] 
Nunes, R. R., Barbosa, C., \& Pimentel, M. (2008). Técnica Entrevista como Dinâmica Educacional. Proceedings of the XIX Simpósio Brasileiro de Informática na Educação, Fortaleza, CE: Sociedade Brasileira de Computação. [GS Search]

Papert, S. M. (1985). Logo: Computadores e Educação. São Paulo, Editora, Brasiliense (edição original EUA 1980).

Peffers, K., Tuunanen, T., Rothenberger, M. A., \& Chatterjee, S. (2008). A design science research methodology for information systems research. Journal of Management Information Systems (JMIS), 24 (3), 45-77. [GS Search]

Pimentel, M. (1998). Brincando de Geometria com Caco e Bia. Proceedings of the IV Workshop de Informática na Escola (pp. 631). Belo Horizonte, MG: Sociedade Brasileira de Computação.

Pimentel, M. (2006). RUP-3C-Groupware: um processo de desenvolvimento de groupware baseado no modelo 3C de colaboração. Proceedings of the III Simpósio Brasileiro de Sistemas de Informação. Curitiba, PR.

Pimentel, M. (2011). Estudo de Caso em sistemas colaborativos. In M. Pimentel \& H. Fuks (Eds.) Sistemas Colaborativos (capítulo 25). Rio de Janeiro: SBC/Elsevier. Retrieved from https://www.dropbox.com/sh/ftcq79y2aqq16u4/_sFxQwE8iO

Pimentel, M. (2017). Tagarelas: sistema de rede social de bate-papo para Educação a Distância. Projeto de pesquisa, UNIRIO.

Pimentel, M., \& Sampaio, F. F. (2001). HiperDiálogo: uma ferramenta de bate-papo para diminuir a perda de co-texto. Proceedings of the XII Simpósio Brasileiro de Informática na Educação (p. 253-266). Vitória, ES: Sociedade Brasileira de Computação. Retrieved from http://br-ie.org/pub/index.php/sbie/article/view/118 [GS Search]

Pimentel, M., \& Sampaio, F. F. (2002). Comunicografia: uma metodologia para análise de processos de interação que se desenvolvem nas ferramentas de comunicação textual da Internet utilizadas no contexto de Educação a Distância. Revista Brasileira de Informática na Educação, 10(1), 53-59. Retrieved from http://www.brie.org/pub/index.php/rbie/article/view/2229 [GS Search]

Pimentel, M., Filippo, D., \& Santos, T. M. (2015). Projetando o futuro da educação com computação ubíqua. Educação \& Imagem (UERJ), 5, 1-4.

Pimentel, M., Fuks, H., \& Lucena, C. J. P. (2003). Debati, debati... aprendi? Investigações sobre o papel educacional das ferramentas de bate-papo. Proceedings of the IX Workshop de Informática na Escola (pp. 167-178). Campinas, SP: Sociedade Brasileira de Computação. Retrieved from http://www.br-ie.org/pub/index.php/wie/article/view/775 [GS Search]

Pimentel, M., Souza, T. P. (1996). AlgGraf: Ambiente Educacional aplicado a Algoritmos e Grafos. Proceedings of the VII Simpósio Brasileiro de Informática na Educação (pp. 1527). Belo Horizonte, MG: Sociedade Brasileira de Computação.

Popper, K. (1989). Em busca de um mundo melhor. Lisboa: Fragmentos. Retrieved from https://www.passeidireto.com/arquivo/1602163/karl_popper1_em_busca_de_um_mundo_m elhor

Prova de conceito. (n.d.). In: Wikipédia: a enciclopédia livre. Retrieved Julho 04, 2017, from https://pt.wikipedia.org/wiki/Prova de conceito

Referenciais de Formação para os Cursos de Graduação em Computação 2017. (2017). Retrieved from http://www.sbc.org.br/documentos-da-sbc/send/127-educacao/1155referenciais-de-formacao-para-cursos-de-graduacao-em-computacao-outubro-2017 
Revista Brasileira de Informática na Educação. (n.d.). Retrieved Julho 04, 2017, from http://www.br-ie.org/pub/index.php/rbie

Sampaio, F. F., \& Pimentel, M. (2000). Comunicografia: uma metodologia para análise de processos de interação que se desenvolvem nas ferramentas de comunicação textual da internet utilizadas no contexto de educação a distância. Proceedings of the XI Simpósio Brasileiro de Informática na Educação (pp. 83-96). Maceió, AL: Sociedade Brasileira de Computação. [GS Search]

Santos, E. O. (2015). Pesquisa-Formação na Cibercultura [ebook]. Whitebooks.

Santos, R. (2015). Formação de formadores e educação superior na cibercultura: itinerâncias de grupos de pesquisa no Facebook (Tese de Doutorado). ProPEd-UERJ. Retrieved from http://www.proped.pro.br/teses/teses_pdf/2010 1-505-DO.pdf

Santos, T. M., Filippo, D., \& Pimentel, M. (2015). Computação Ubíqua para apoiar a educação musical: explorações com o Makey Makey. Proceedings of the XXI Workshop de Informática na Escola (pp. 330-339). Maceió, AL: Sociedade Brasileira de Computação. doi: $10.5753 /$ cbie.wie.2015.330 [GS Search]

Santos, T. M., Pimentel, M., \& Filippo, D. (2016). Tapetes Musicais Inteligentes: Computação Ubíqua para apoiar a Educação Musical. Revista Brasileira de Informática na Educação, 24, 123-142. doi: 10.5753/rbie.2016.24.02.123 [GS Search]

Silva, A. R. (2016). Gamificação e inteligência coletiva para promover a participação em sistema de bate-papo para educação. Dissertação de Mestrado em Informática. UNIRIO, Rio de Janeiro, 2016. Retrieved from http://www2.uniriotec.br/ppgi/banco-de-dissertacoesppgi-unirio/ano-2016/gamificacao-e-inteligencia-coletiva-para-promover-a-participacaoem-sistema-de-bate-papo-para-educacao/view [GS Search]

Silva, V., Pimentel, M., \& Dias, V. M. (2015). Bate-papo Colaborativo ou Centrado no Professor? In: XXVI Simpósio Brasileiro de Informática na Educação, Maceió. doi: $\underline{10.5753 / \text { cbie.sbie.2015.1303 [GS Search] }}$

Simon, H. (1969). The Sciences of the Artificial. Cambridge: MIT Press. [GS Search]

Soares, M. (2013). Pesquisas com os cotidianos: devir-filosofia e devir-arte na ciência. Educação \& Realidade. Porto Alegre, 38 (3), 731-745. Retrieved from http://www.seer.ufrgs.br/educacaoerealidade/article/view/22829 [GS Search]

Vaishnavi, V. K., \& Kuechler Jr., W. (2015). Design Science Research in Information Systems. Documento online: <http://desrist.org/design-research-in-information-systems/>. Acesso em 14 jun 2017.

Wainer, J. (2007). Métodos de pesquisa quantitativa e qualitativa para a ciência da computação. In: Tomasz Kowaltowski, Karin Breitman. (Org.). Jornada de Atualização em Informática (SBC/JAI), 2007, p. 221-262. [GS Search]

Wainer, J. (2011). Experimento em sistemas colaborativos. In M. Pimentel \& H. Fuks (Eds.) Sistemas Colaborativos (capítulo 24). Rio de Janeiro: SBC/Elsevier. Retrieved from https://www.dropbox.com/sh/ftcq79y2aqq16u4/sFxQwE8iO

Wazlawick, R. S. (2008). Metodologia de pesquisa para ciência da computação. Rio de Janeiro: Elsevier. [GS Search]

Workshop de Informática na Escola. (2017). Retrieved Julho 04, 2017, from https://sabertecnologias.com.br/cbie/index.php/eventos-paralelos-e-submissoes/wie

Wieringa, R. J. (2014). Design Science Methodology for Information Systems and Software Engineering. Heidelberg: Springer. 
XXVIII SBIE - Simpósio Brasileiro de Informática na Educação. (2017). Retrieved Julho 04, 2017, from https://sabertecnologias.com.br/cbie/index.php/eventos-paralelos-e$\underline{\text { submissoes/sbie/ }}$

Yin, R. K. (2005). Estudo de caso: planejamento e métodos (3rd ed.). Porto Alegre, RS: Bookman. 